\begin{tabular}{|c|c|}
\hline \multirow{2}{*}{ MAGNA } & Research Article \\
MEDIKA & Berkala Ilmiah Kedokteran dan Kesehatan \\
& Journal Page: https://jurnal.unimus.ac.id/index.php/APKKM \\
\hline
\end{tabular}

\title{
The Effect of Oral Sildenafil on the Decrease in the Degree of Pulmonary Artery Systolic Pressure in PPHN Infants at Siti Khodijah Muhammadiyah Hospital Sepanjang
}

\author{
Muhammad Afif ${ }^{1}$, Muhammad Perdana Airlangga $^{2}$, Nurma Yuliyanasari ${ }^{3}$, Gina Noor Djalilah $^{4}$ \\ 1,2,3) Medical Faculty, University Muhammadiyah of Surabaya
}

\begin{tabular}{l}
\hline \multicolumn{1}{c}{ Article Info } \\
\hline Article history: \\
Received 15 December 2020 \\
Revised 17 December 2020 \\
Accepted 24 January 2021 \\
Available online 01 February 2021 \\
\hline Keywords: \\
Severity PASP, oral sildenafil, \\
PPHN \\
\hline Correspondence: \\
afifmuhammad019@gmail.com \\
\hline
\end{tabular}

How to cite this article:

1. Afif M, Airlangga MP, Yuliyanasari N, Djalilah GN. The Effect of Oral Sildenafil on the Decrease in the Degree of Pulmonary Artery Systolic Pressure in PPHN Infants at Siti Khodijah Muhammadiyah Hospital Sepanjang. MAGNA MEDIKA Berk Ilm Kedokt dan Kesehat. 2021;8(1):18-28

\begin{tabular}{l} 
Abstract \\
\hline Background: Persistent Pulmonary Hypertension of the Newborn \\
(PPHN) is a condition of the failure to decrease pulmonary artery \\
pressure, so that blood pressure in the lungs remains high, as in a fetus. \\
PPHN cases are 2-6 of 1000 live births and responsible for $10 \%$ of \\
confirmed deaths in the neonatal intensive care unit (NICU). Sildenafil is \\
vasodilator that can be used to reduce pulmonary artery systolic pressure \\
(PASP), morbidity, and mortality in PPHN infants. \\
Objective: To analyze the effect of sildenafil on decrease the severity of \\
pulmonary artery systolic pressure in PPHN infants. \\
Method: This is an analytic observational study with cross-sectional \\
design. The samples were collected using consecutive sampling on 30 \\
PPHN infant patients in 2018. The data were collected from medical \\
records of PPHN infant patients, then assessing the severity value of \\
PASP which obtained from echocardiography result. The severity of \\
PASP is classified into normal (PASP $\leq 35$ mmHg), mild (PASP36-45 \\
mmHg), moderate (PASP $45-60$ mmHg), and severe (PASP $>60$ mmHg) \\
Results: This study showed that 27 PPHN infant patients have \\
decreased PASP level to normal, previously from mild 7 infants ( $23.3 \%)$, \\
moderate 16 infants (53.3\%), and severe 4 infants (13\%), after being given \\
oral sildenafil. There were 1 (3.3\%) infant patient remained severes, 1 \\
(3.3\%) patient was decreased from severe to moderate, and 1 patient \\
(3.3\%) was decreased from severe to mild. The p value < $<0.05$ was \\
obtained, so oral sildenafil significantly decreased the PASP severity in \\
PPHN infants patients. \\
Conclusion: There is a beneficial effect of oral sildenafil on decreasing \\
the severity of pulmonary artery systolic pressure in PPHN infants at the \\
NICU of Siti Khodijah Muhammadiyah Hospital Sepanjang. \\
\hline MEDIKA: Berkala Ilmiah Kedokteran dan Kesehatan with CC BY NC SA license
\end{tabular}




\section{PENDAHULUAN}

Persistent Pulmonary Hypertension of the Newborn (PPHN) merupakan keadaan dimana proses transisi vaskuler pada paru dari masa janin ke neonatus, yakni Pulmonary Vaskuler Resistance (PVR) gagal turun menjadi normal sehingga tahanan vaskuler paru tetap seperti pada saat masih janin yakni tetap tinggi ${ }^{1}$. Setelah 72 jam setelah kelahiran tekanan sistolik arteri pulmonalis/pulmonary artery systolic pressure (PASP) normal bayi baru lahir (PASP 37 44,97 $\mathrm{mmHg})^{2}$. PPHN merupakan kasus yang serius karena dapat menyebabkan morbiditas berupa kecacatan neurologis dan mortalitas yang dikarenakan penurunan oksigen ke organ sehingga tatalaksana yang cepat akurat dan rasional sangat diperlukan ${ }^{1}$.

Angka kejadian kasus PPHN yaitu 2-6 dari 1000 kelahiran hidup atau sekitar 10\% dari kematian yang terkonfirmasi pada neonatal intensif care unit (NICU) dengan disertai sekitar 8-10\% mengiringi terjadinya risiko morbiditas dan kematian ${ }^{3}$. Sumber lain juga menjelaskan prevalensi bayi PPHN sekitar 0,34-6,8 per 1000 kelahiran hidup dan diiringi dengan tingkat kematian mencapai 1020\% dari kasus ${ }^{4}$. Penelitian Lasmono et al (2018) di surabaya menjelaskan selama periode april sampai september tahun 2017 prevalensi PPHN adalah 42 bayi per 1000 kelahiran hidup 5 .

Penegakan diagnosis yang menjadi gold standart untuk PPHN yakni ekokardiografi serta kasus kelainan struktural bisa disingkirkan ${ }^{6}$. Pada penelitian- penelitian yang dilakukan banyak menggunakan tekanan arteri pulmonalis dan kecepatan maksimal regurgitasi trikuspid sebagai parameter saat ini dan Pulmonary Artery Systolic Pressure (PASP) atau tekanan sistolik arteri pulmonalis adalah yang digunakan pada penelitian ini. Nilai batas normal PASP adalah $\leq 35 \mathrm{mmHg}$. Kemudian pembagian grup PASP menurut tingkat keparahannya terbagi menjadi ringan (PASP 36-45 mmHg), sedang (PASP 45-60) dan berat $(\mathrm{PASP}>60 \mathrm{mmHg})^{2,7,8}$.

Perlunya terapi PPHN ditujukan agar mencegah morbiditas dan mortalitas yang tinggi tersebut pada bayi PPHN baru lahir. Terapi PPHN sendiri sebenarnya sudah memiliki beberapa pilihan terapi yang dapat menurunkan angka morbiditas dan mortalitas pada bayi dengan PPHN yang diluar negeri biasanya digunakan sebagai terapi misalnya ventilator, golongan inotropik dan Extracorporeal Membrane Oxygenation (ECMO). Namun, pilihan-pilihan terapi yang banyak digunakan saat ini masih mempunyai efek samping misalnya pada terapi inhaled Nitrit Oxide iNO kadang-kadang akan terjadi rebound pulmonary bipertension pada bayi apabila terapi dihentikan ${ }^{4}$.

Sildenafil merupakan terapi pada bayi PPHN yang saat ini digunakan dan memberikan pengaruh perbaikan klinis berupa penurunan tekanan arteri pulmonalis. Sildenafil adalah Phosphodiesterase 5 yang merupakan isomer Phosphodiesterase yang dominan di paru yang memetabolisir c-GMP. Sildenafil akan menyebabkan vasokontriksi pembuluh darah yakni dengan mekanisme 
mendegradasi c-GMP menjadi GMP ${ }^{9,10}$. Dosis pemberian sildenafil pada bayi dengan hipertensi pulmonal yang digunakan saat ini adalah $0,5 \mathrm{mg}$ dan jika tidak responsive bisa diberikan dosis maksimal $2 \mathrm{mg}$ setelah evaluasi setiap $6 \mathrm{jam}^{3}$. Pemberian Sildenafil oral akan menyebabkan penurunan dari tekanan arteri pulmonalis dengan cara merelaksasikan otot polos pembuluh arteri

\section{METODE PENELITIAN}

Penelitian ini merupakan penelitian observasional analitik dengan metode rancangan penelitian cross sectional. Populasi pada penelitian ini adalah seluruh pasien bayi dengan PPHN di NICU Rumah Sakit Siti Khodijah Muhammadiyah Cabang Sepanjang. Subyek penelitian diambil dengan metode consecutive sampling yakni mengambil data rekam medis yang sesuai dengan kriteria inklusi dan ekslusi sampai jumlah sampel terpenuhi. Jumlah sampel pada penelitian ini 30 pasien bayi PPHN yang diberikan sildenafil oral sebagai terapi pada tahun 2018. Pengamatan dilakukan dengan melihat data rekam medis pasien PPHN dengan mengamati nilai derajat tekanan sistolik arteri pulmonalis (PASP) yang didapat dari hasil ekokardiografi yang ada pada rekam medis bayi PPHN. Derajat PASP terbagi menjadi kelompok normal (PASP $\leq 35 \mathrm{mmHg}$ ), kelompok ringan sehingga terjadi vasodilatasi arteri pulmonalis ${ }^{11}$. Oleh karena hal tersebut, peneliti ingin membuktikan adanya pengaruh pemberian sildenafil oral pada bayi dengan PPHN. Pembuktian pengaruh sildenafil oral ini dengan menganalisis hasil derajat dari PASP sebelum dan sesudah pemberian sildenafil oral pada bayi PPHN.

(PASP 36-45 mmHg), kelompok sedang (PASP 45-60 mmHg) dan kelompok berat (PASP > 60 $\mathrm{mmHg}$ ). Pada penelitian ini, pengambilan data rekam medis dilakukan setelah mendapat izin etik dari Komite Etik Penelitian Kesehatan (KEPK) Rumah Sakit Siti Khodijah Muhammadiyah Cabang Sepanjang dengan nomor surat etik No. 026/KET-KEPK/XII-2019. Hasil pengamatan data rekam medis tersebut kemudian diolah melalui proses editing, coding, entry dan tabulating dan selanjutnya dilakukan analisis data menggunakan uji wilcoxon menggunakan SPSS versi 25 . Kemudian dari hasil data analisis tersebut didapatkan kesimpulan dari penelitian ini.

\section{HASIL}

\section{Karakteristik subyek}

1) Jenis Kelamin

Tabel 1 Deskripsi jenis kelamin bayi PPHN

\begin{tabular}{lcc}
\hline Jenis Kelamin & $\mathrm{n}$ & $\%$ \\
\hline Laki-laki & 14 & 46,7 \\
Perempuan & 16 & 53,3 \\
\hline Total & 30 & 100 \\
\hline
\end{tabular}


Tabel 1 Menjelaskan bahwa pasien bayi PPHN sebagian besar merupakan perempuan yakni

\section{2) Usia Kehamilan}

Berdasarkan Tabel 2 menjelaskan bahwa pasien bayi PPHN sebagian besar merupakan bayi aterm atau cukup bulan yakni sebanyak 17 bayi (56,7\%) sebanyak 16 bayi $(53,3 \%)$ sedangkan laki-laki yaitu sebanyak 14 bayi $(46,7 \%)$.

sedangkan bayi yang prematur atau kurang bulan adalah sebanyak 13 bayi (43,3\%).

Tabel 2 Deskripsi usia kehamilan bayi PPHN

\begin{tabular}{lcc}
\hline Usia kelahiran & $\mathrm{n}$ & $\%$ \\
\hline Prematur & 13 & 43,3 \\
Aterm & 17 & 56,7 \\
\hline Total & 30 & 100 \\
\hline
\end{tabular}

\section{3) Rerata Berat Badan Bayi PPHN}

Tabel 3 Deskripsi rerata berat badan bayi PPHN

\begin{tabular}{lcc}
\hline Rerata berat badan bayi (gr) & $\mathrm{n}$ & SD \\
\hline 2545 & 30 & 622,05 \\
\hline
\end{tabular}

Hasil data Tabel 3 menjelaskan bahwa bayi PPHN pada penelitian ini memiliki rerata berat badan sebanyak 30 bayi adalah sebesar Hasil data Tabel 4 menjelaskan bahwa sebagian besar jenis persalinan bayi PPHN pada penelitian ini adalah sectio caesaria (SC)
2545 gr dengan standar deviasi (SD) adalah 622,05 .

\section{4) Jenis Persalinan}

yakni sebanyak 25 bayi $(83,3 \%)$ sedangkan kelahiran spontan sebesar 5 bayi $(16,7 \%)$.

Tabel 4 Deskripsi Jenis Persalinan pada bayi PPHN

\begin{tabular}{lcc}
\hline Jenis Persalian & $\mathrm{n}$ & $\%$ \\
\hline Spontan & 5 & 16,7 \\
SC & 25 & 83,3 \\
\hline Total & 30 & 100 \\
\hline
\end{tabular}

\section{5) Rerata Tekanan Sistolik Arteri Pulmonalis Sebelum dan sesudah pemberian sildenafil oral}

Hasil data Tabel 5 menjelaskan bahwa bayi PPHN pada penelitian ini memiliki rerata tekanan arteri pulmonalis sebelum pemberian sildenafil oral adalah 51,13 $\mathrm{mmHg}$ dengan standar deviasi adalah 16,65. Dan rerata tekanan arteri pulmonalis sesudah pemberian sildenafil oral adalah 30,73 $\mathrm{mmHg}$ degang standar deviasi adalah 8,71. 
Tabel 5 Deskripsi Rerata tekanan sistolik arteri pulmonalis bayi PPHN sebelum dan sesudah pemberian sildenafil oral

\begin{tabular}{lccc}
\hline Rerata tekanan sistolik arteri pulmonalis $(\mathrm{mmHg})$ & $\mathrm{n}$ & $\mathrm{SD}$ \\
\hline Sebelum & 51,13 & 30 & 16,65 \\
Sesudah & 31,31 & 30 & 8,71 \\
\hline
\end{tabular}

\section{6) Penyakit Jantung Bawaan pada Bayi PPHN}

Hasil data tabel 6 menjelaskan bahwa sebagian besar bayi PPHN pada penelitian ini mempunyai penyakit jantung bawaan yakni sebanyak 29 bayi dan 1 bayi tidak dengan penyakit jantung bawaan. Dan penyakit jantung bawaan pada penelitian ini adalah ASD sebanyak 11 bayi ( 36,7\%), PDA sebanyak 2 bayi (6,7\%), PFO sebanyak 1 bayi (3,3\%), ASD+PDA sebanyak 13 bayi (43,3\%), ASD + PFO sebanyak 1 bayi dan VSD+ASD+PDA sebanyak 1 bayi (3,3\%).

Tabel 6 Deskripsi penyakit jantung bawaan pada bayi PPHN

\begin{tabular}{lcc}
\hline Penyakit jantung bawaan & $\mathrm{n}$ & $\%$ \\
\hline Tidak ada & 1 & 3,3 \\
VSD & 0 & 0 \\
ASD & 11 & 36,7 \\
PDA & 2 & 6,7 \\
PFO & 1 & 3,3 \\
VSD+ASD & 0 & 0 \\
VSD+PDA & 0 & 0 \\
ASD+PDA & 13 & 43,3 \\
ASD+PFO & 1 & 3,3 \\
PDA+PFO & 0 & 0 \\
VSD+PFO & 0 & 0 \\
VSD+ASD+PDA & 1 & 3,3 \\
VSD+ASD+PFO & 0 & 0 \\
VSD+PFO+PDA & 0 & 0 \\
PFO+ASD+PDA & 0 & 0 \\
VSD+ASD+PDA+PFO & 0 & 0 \\
\hline Total & 30 & 100 \\
\hline
\end{tabular}

\section{7) Rerata Lama Perawatan pada bayi PPHN}

Tabel 7 Deskripsi rerata lama perawatan pada bayi PPHN

\begin{tabular}{lcc}
\hline Rerata lama Perawatan (Hari) & $\mathrm{n}$ & $\mathrm{SD}$ \\
\hline 8,43 & 30 & 2,48 \\
\hline
\end{tabular}


Hasil data tabel 7 menjelaskan bahwa bayi

PPHN pada penelitian ini memiliki rerata lama perawatan sebanyak 30 bayi adalah 8,43 hari dengan standar deviasi adalah 2,48.

\section{8) Deskripsi Rerata PASP dengan PJB dan Non-PJB}

Hasil data tabel 8 menjelaskan bahwa bayi PPHN dengan PJB pada penelitian ini memiliki rerata PASP sebesar 51,34 mmHg dengan standar deviasi 16,90. Sedangkan pada PPHN dengan non-PJB memliki nilai PASP sebesar $45 \mathrm{mmHg}$.

Tabel 8 Deskripsi Rerata PASP dengan PJB dan Non-PJB

\begin{tabular}{llcc}
\hline Rerata tekanan sistolik arteri pulmonalis $(\mathrm{mmHg})$ & $\mathrm{n}$ & $\mathrm{SD}$ \\
\hline PPHN dengan PJB & 51,34 & 29 & 16,90 \\
PPHN non PJB & 45 & 1 & - \\
\hline
\end{tabular}

Pengaruh Pemberian Sildenafil Oral Terhadap Derajat PASP pada Bayi PPHN

Tabel 9 Pengaruh derajat PASP sebelum dan sesudah diberikan sildenafil oral

\begin{tabular}{llccccc}
\hline \multirow{2}{*}{ Derajat PASP } & \multicolumn{5}{c}{ Sesudah } & \multirow{2}{*}{ Nilai p } \\
\cline { 3 - 6 } & Normal & Normal & Ringan & Sedang & Berat & \\
\cline { 3 - 6 } Sebelum & $0 \%)$ & $0(0 \%)$ & $0(0 \%)$ & $0(0 \%)$ & \\
& Ringan & $7(23,3 \%)$ & $0(0 \%)$ & $0(0 \%)$ & $0(0 \%)$ & \multirow{2}{*}{$<<0,05$} \\
& Sedang & $16(53,3 \%)$ & $0(0 \%)$ & $0(0 \%)$ & $0(0 \%)$ & \\
& Berat & $4(13 \%)$ & $1(3,3 \%)$ & $1(3,3 \%)$ & $1(3,3 \%)$ & \\
\hline \multirow{2}{*}{ Total } & 27 & 1 & 1 & 1 & 30 \\
\hline
\end{tabular}

Hasil data tabel 9 menjelaskan bahwa bayi PPHN pada penelitian ini terdapat 27 bayi yang derajat PASP turun menjadi normal. Yakni yang awalnya dari derajat ringan yaitu 7 bayi $(23,3 \%)$, derajat sedang 16 bayi $(53,3 \%)$ dan derajat berat 4 bayi $(13 \%)$ sesudah diberikan sildenafil oral turun menjadi normal. Kemudian 1 pasien bayi (3,3\%) awalnya derajat berat tetap derajat berat, 1 pasien bayi $(3,3 \%)$ awalnya derajat berat menjadi derajat sedang dan 1 pasien bayi (3,3\%) awalnya derajat berat menjadi derajat ringan. Kemudian nilai $\mathrm{p}<$ 0,05 menjelaskan bahwa sildenafil oral

berpengaruh terhadap penurunan derajat PASP pada bayi PPHN.

\section{PEMBAHASAN}

Pada data tabel 1 pasien bayi PPHN sebagian besar merupakan perempuan yakni sebanyak 16 bayi $(53,3 \%)$ sedangkan laki-laki yaitu sebanyak 14 bayi $(46,7 \%)$. Hal ini sesuai dengan penelitian Lasmono et al (2018) yang menjelaskan bahwa perempuan yang lebih besar persentasinya dibandingkan laki-laki yakni perempuan 67\% dan laki-laki 33\%5. Juga sesuai dengan penelitian Harerimana et al (2018) bahwa angka kejadian 
PPHN pada pada perempuan sebesar $51,4^{0} \%^{12}$. Hal ini berhubungan dengan hormon seks pada perempuan yakni estrogen, autoimun ataupun kelainan genetik pada kromoson yang mendukung terjadinya penyakit tersebut ${ }^{13}$. Pada data tabel 2 pasien bayi PPHN sebagian besar merupakan bayi aterm atau cukup bulan yakni sebanyak 17 bayi (56,7\%) sedangkan bayi yang prematur atau kurang bulan adalah sebanyak 13 bayi (43,3\%). Hal ini sesuai dengan penelitian Begum et al (2019) yang menjelaskan bahwa Meconium aspiration Syndrome (MAS) pada bayi PPHN merupakan faktor risiko yang signifikan yang terjadi pada usia kehamilan aterm. Hubungan faktor risiko kejadian PPHN dengan MAS adalah non-aktifnya surfaktan yang disebabkan peradangan paru dan hipoksia. Peradangan paru dan hipoksia menyebabkan tekanan sistolik arteri pulmonalis menjadi tinggi ${ }^{14}$.

Pada data tabel 3 didapatkan hasil bayi PPHN pada penelitian ini memiliki rerata berat badan sebanyak 30 bayi adalah sebesar 2545 gr dengan standar deviasi (SD) adalah 622,05. Hal ini sesuai dengan penelitian Begum et al (2019) yang menjelaskan bahwa karakteristik rerata berat badan bayi lahir pada PPHN memiliki nilai rerata berat badan lahir normal yakni 2598 dengan SD $760,35^{14}$. Dan Sesuai juga dengan penelitian Allawama et al (2019) menjelaskan rerata berat badan bayi lahir adalah 2800 gram dengan SD adalah 467 pada bayi $\mathrm{PPHN}^{15}$. Pada penelitian ini menjelaskan bahwa sebagian besar jenis persalinan bayi PPHN pada penelitian ini adalah sectio caesaria (SC) yakni sebanyak 25 bayi $(83,3 \%)$ sedangkan kelahiran spontan sebesar 5 bayi (16,7\%). Hubungan antara Sectio caesaria (SC) dengan PPHN adalah meningkatknya risiko tekanan arteri pulmonalis disebabkan beberapa hal yakni produksi NO, cGMP endogen terbatas, sintesis CO, kadar antioksidan yang lebih rendah pada bayi baru lahir serta risiko RDS pada bayi $\mathrm{SC}^{16,17}$

Hasil tabel 5 didapatkan hasil rerata tekanan arteri pulmonalis sebelum pemberian sildenafil oral adalah 51,13 $\mathrm{mmHg}$ dengan standar deviasi adalah 16,65. Dan rerata tekanan arteri pulmonalis sesudah pemberian sildenafil oral adalah 30,73 $\mathrm{mmHg}$ degang standar deviasi adalah 8,71. Hal ini sesuai dengan penelitian Agha et al (2017) yang menjelaskan PASP turun hingga 38,37 $\mathrm{mmHg}$ dengan SD 8,1 yang sebelum terapi memiliki PASP $61,7 \mathrm{mmHg}$ dengan SD $7,1^{18}$. Sesuai juga dengan Shrestha et al (2017) PASP grup yang diberikan pengobatan sildenafil turun dari yang awalnya PASP $75,9 \mathrm{mmHg}$ dengan SD 17,89 turun menjadi PASP $66,03 \mathrm{mmHg}$ dengan SD 19,62 ${ }^{19}$. Penelitian ini bayi PPHN yang mempunyai penyakit jantung bawaan yakni sebanyak 29 bayi dan 1 bayi tidak dengan penyakit jantung bawaan. Dan penyakit jantung bawaan pada penelitian ini adalah ASD sebanyak 11 bayi ( 36,7\%), PDA sebanyak 2 bayi (6,7\%), PFO sebanyak 1 bayi (3,3\%), ASD+PDA sebanyak 13 bayi (43,3\%), ASD+PFO sebanyak 1 bayi dan $\mathrm{VSD}+\mathrm{ASD}+\mathrm{PDA}$ sebanyak 1 bayi (3,3\%). Seberapa besar tekanan arteri pulmonalis 
dipengaruhi aliran darah dari kanan kekiri. Tekanan aliran yang ada pada jantung dipengaruhi adanya defek ASD, VSD, dan PDA sehingga mempengaruhi tekanan arteri pulmonalis ${ }^{5}$. Demikian pula dengan PFO menyebabkan peningkatkan vaskular paru disertai dengan disfungsi ventrikel kiri ${ }^{20}$. Meconium Aspration Syndrome dapat menjadi penyebab terjadinya PPHN pada 1 bayi yang tidak memeliki penyakit jantung bawaan. Sesuai dengan penelitian Rocha, Maria dan Hercilia (2012) PPHN berhubungan dengan penyakit parenkim paru, MAS dan RDS. Hal tersebut dikarenakan karena peradangan paru surfaktan nonaktif dan menyebabkan vasokonstriksi vaskular sehingga tekanan arteri pulmonalis tinggi ${ }^{21}$.

Pada tabel 7 menjelaskan bahwa bayi PPHN pada penelitian ini memiliki rerata lama perawatan sebanyak 30 bayi adalah 8,43 hari dengan standar deviasi adalah 2,48. Pada penelitian ini durasi atau rata-rata lama perawatan bayi berbeda dengan penelitian sebelumnya Agha et al (2017) yakni rata-rata 4,4 hari dengan standar deviasi 1,94 dengan dosis 0,78 $\pm 0,2 \mathrm{mg} / \mathrm{kg} / 6-12$ jam. Perbedaan dosis yang diberikan kepada bayi selama perawatan di NICU serta pada penelitian ini juga selain sildenafil juga diberikan dobutamin yang kemungkinan menjadi penyebab perbedaan ${ }^{18}$.

Pada tabel 8 menjelaskan bahwa bayi PPHN dengan PJB pada penelitian ini memiliki rerata PASP sebesar 51,34 mmHg dengan standar deviasi 16,90. Sedangkan pada PPHN dengan
non-PJB memliki nilai PASP sebesar $45 \mathrm{mmHg}$. Sesuai dengan penelitian Zavaleta, Maria dan Eulo (2015) PASP pada bayi PPHN dengan non-PJB memiliki PASP yang lebih rendah dibandingkan bayi PPHN dengan PJB. Hal ini karena adanya PJB akhimya membebani kerja ventrikel sehingga mempengaruhi tekanan sistolik arteri pulmonalis ${ }^{22}$.

Pada penelitian ini menjelaskan bahwa bayi PPHN pada penelitian ini terdapat 27 bayi yang derajat PASP turun menjadi normal. Yakni yang awalnya dari derajat ringan yaitu 7 bayi $(23,3 \%)$, derajat sedang 16 bayi $(53,3 \%)$ dan derajat berat 4 bayi (13\%) sesudah diberikan sildenafil oral turun menjadi normal. Kemudian 1 pasien bayi (3,3\%) awalnya derajat berat tetap derajat berat, 1 pasien bayi $(3,3 \%)$ awalnya derajat berat menjadi derajat sedang dan 1 pasien bayi (3,3\%) awalnya derajat berat menjadi derajat ringan. Kemudian nilai $\mathrm{p}<$ 0,05 menjelaskan bahwa sildenafil oral berpengaruh terhadap penurunan derajat PASP pada bayi PPHN. Hal ini sesuai dengan hasil penelitian Prithviraj et al (2016) Semua bayi mengalami penurunan tekanan arteri paru yang signifikan pada semua bayi dengan ventilasi noninvasif ${ }^{3,17}$. Sesuai juga dengan hasil penelitian Lasmono, Mahrus dan Teddy (2018) menyebutkan bahwa 20 anak pada kelompok sildenafil setelah pemberian sildenafil oral memberikan perbaikan klinis berupa penurunan tekanan arteri pulmonalis 5 .

Mekanisme yang terjadi adalah pada pasien PPHN didapatkan peningkatan signifikan dari 
ekspresi PDE5 di paru-paru sehingga mengalami kontraksi pembuluh darah paru yang mengakibatkan vasokontriksi pembuluh darah paru sehingga PASP atau tekanan sistolik arteri pulmonalis menjadi lebih tinggi. Kemudian mekanisme sildenafil adalah memiliki kandungan yaitu PDE5 inhibitor dan memiliki kemampuan untuk menurunkan efek dari nitrit oxide(NO). NO merangsang otot polos yang ada pada pembuluh darah untuk relaksasi dan vasodilatasi yang merupakan efek dari jalur cyclic guanosine monophosphate (cGMP) $)^{11,23,24}$.

Dosis yang digunakan pada penelitian ini adalah $0,5 \mathrm{mg} / \mathrm{kg} / \mathrm{kali}$ setiap 6 jam hal ini sesuai dengan Penelitian Prithviraj et al (2016) menjelaskan bahwa dosis awal pemberian sildenafil oral adalah 0,5 $\mathrm{mg}$ dan dosis maksimal pemberian $2 \mathrm{mg}$ setelah evaluasi setiap 6 jam jika tidak responsif dengan menggunakan Oral gastric Tube (OGT) ${ }^{3}$.

Dari hasil penelitian ini terdapat satu data yang tidak mengalami penurunan tekanan sistolik arteri pulmonalis yang awalnya derajat PASP berat dan setelah pemberian derajat PASP tetap berat. Hal ini bisa dikarenakan oleh penyakit jantung bawaan yang diderita oleh bayi tersebut yang mengalami $\mathrm{VSD}+\mathrm{ASD}+\mathrm{PDA}$ sesuai pada penelitian Zeng et al (2011) menjelaskan bahwa hipertensi arteri pulmonalis dengan dengan VSD dan PDA lebih parah tingkatannya dibandingkan dengan ASD sehingga menjadi kurang responsif terhadap terapi yang diberikan ${ }^{25}$.

Hasil nilai $\mathrm{p}$ menunjukkan $\mathrm{p}=0,00 \quad(\mathrm{p}<0,05)$ menjelaskan penelitian ini signifikan Ho ditolak yang berarti sildenafil oral berpengaruh terhadap penurunan derajat PASP pada bayi PPHN.

\section{KESIMPULAN}

Berdasarkan penelitian diketahui bahwa terdapat pengaruh sildenafil oral terhadap penurunan derajat tekanan sistolik arteri pulmonalis pada bayi PPHN di NICU RS Siti Khodijah Muhammadiyah Cabang Sepanjang.

\section{Kelebihan, Kekurangan Penelitian dan Potensi Pengembangan}

Penelitian ini menggunakan ekokardiografi untuk memantau nilai PASP pada bayi PPHN dengan membandingkan hasil ekokardiografi yang dikelompokkan berdasarkan derajat PASP sebelum dan sudah diberikan sildenafil oral pada bayi PPHN yang berada di NICU. Namun, dibandingkan ekokardiografi menggunakan katerisasi spesifitas dan akurasinya masih lebih bagus karena merupakan standar yang baku untuk penegakan diagnosis hipertensi arteri pulmonalis. Jangka waktu ekokardiografi pada penelitian ini berbeda-beda. Kemudian pemberian dengan selang OGT juga dapat menyebebakan dosis yang diberikan menjadi tidak sesuai kebutuhan namun pemberian sildenafil cukup mudah dalam pemberiannya, efek samping yang minimal dan murah.

Diperlukan penelitian lebih lanjut dengan jangka waktu ekokardiografi sama dan progres ketika sesudah keluar dari NICU. Diperlukan juga penelitian lebih lanjut terkait lama perawatan berdasarkan derajat PASP. 


\section{REFERENSI}

1. Ontoseno T. Penyakit jantung pada anak. Jakarta: Sagung Seto; 2018.

2. Kang C, Zhao E, Zhou Y, Zhao H, Liu Y, Gao N, et al. Dynamic changes of pulmonary arterial pressure and ductus arteriosus in human newborns from birth to 72 hours of age. Medicine (Baltimore). 2016;95(3).

3. Prithviraj D, Reddy B, Shetty A, Deepthi, Reddy R. Oral Sildenafil in Persistent Pulmonary Hypertension of the Newborn in Invasive and Non-invasive Ventilated Babies-its Effect on Oxygenation Indices. Int J Sci STUDY. 2016;4(2):203-9.

4. Hussain AS, Ali R, Ahmed S, Naz F, Haroon A. Oral sildenafil use in neonates with persistent pulmonary hypertension of newborn. J Ayub Med Coll Abbottabad. 2017;29(4):677-80.

5. Lasmono SF. Efikasi Dan Safety Beraprost Dalam Menurunkan Tekanan Arteri Pulmonalis Pada Hipertensi Arteri Pulmonalis Terkait Penyakit Jantung Bawaan Pirau Kiri Ke Kanan. Universitas Airlangga; 2018.

6. Bendapudi P, Rao GG, Greenough A. Diagnosis and management of persistent pulmonary hypertension of the newborn. Paediatr Respir Rev. 2015 Jun;16(3):157-61.

7. Main ML, Grayburn PA, Lang RM, Goldman JH, Gibson CM, Sherwin P, et al. Effect of Optison on pulmonary artery systolic pressure and pulmonary vascular resistance. Am J Cardiol. 2013;112(10):165761.

8. Merlos P, Núñez J, Sanchis J, Miñana G, Palau P, Bodí V, et al. Echocardiographic estimation of pulmonary arterial systolic pressure in acute heart failure. Prognostic implications. Eur $J$ Intern Med. 2013;24(6):562-7.

9. Susanto LTM. Sildenafil dalam penatalaksanaan disfungsi ereksi. Susanto, Bagian Histol Fak Kedokt Univ Trisakti. 2013;

10. Koentartiwi D. Efek sildenafil pada hipertensi paru sekunder akibat penyakit jantung bawaan lesi pirau kiri ke kanan= Sildenafil for secondary pulmonary hypertension due to left to right shunt. 2014;

11. Dodgen AL, Hill KD. Safety and tolerability considerations in the use of sildenafil for children with pulmonary arterial hypertension. Drug Healthc Patient Saf. 2015;7:175.

12. Harerimana I, Ballot DE, Cooper PA. Retrospective review of neonates with persistent pulmonary hypertension of the newborn at Charlotte Maxeke Johannesburg Academic Hospital. South African J Child Heal. 2018;12(1):29-33.

13. Manes A, Palazzini M, Dardi F, D’Adamo A, Rinaldi A, Galiè N. Female gender and pulmonary arterial hypertension: a complex 
relationship. $G$ Ital Cardiol (Rome). 2012;13(6):448.

14. Begum NA, Afroze S, Laila R, Siddiqua SP, Rahaman MT. Risk Factors of Persistent Pulmonary Hypertension of Newborn (PPHN) in Different Gestation. Am J Pediatr. 2019;5(3):142-7.

15. Al-lawama M, Badran E, Abdelfattah AS, Jaddalla R, Almahameed HA, Al-Ammouri I. Outcomes of newborn infants with pulmonary hypertension treated with oral sildenafil in a tertiary care center in Amman, Jordan. Int J Clin Pediatr. 2019;8(2):27-31.

16. Babooa N, Shi W-J, Chen C. Factors relating caesarean section to persistent pulmonary hypertension of the newborn. World J Pediatr. 2017;13(6):517-27.

17. Anas M, Triastuti N, Airlangga MP. Role Of Inhaled Nitric Oxides In Pregnancy With Eisenmenger Syndrome. Qanun Med J Fac Med Muhammadiyah Surabaya. 2020;4(1):1126.

18. Agha H, El Tantawy A, Iskander I, Samad AA. Impact of Management Strategies on the Outcome of Persistent Pulmonary Hypertension of the Newborn. Fortune Journals. 2017;

19. Shrestha SK, Srivastava B, Karki M, Khatri DB, Pradhan RM. Effect of sildenafil citrate on pulmonary arterial systolic pressure and sub-maximal exercise capacity in chronic obstructive pulmonary disease. Kathmandu Univ Med J. 2017;15:271-8.

20. Mathew B, Lakshminrusimha S. Persistent pulmonary hypertension in the newborn. Children. 2017;4(8):63.

21. Rocha G, Baptista MJ, Guimarães H. Persistent pulmonary hypertension of non cardiac cause in a neonatal intensive care unit. Pulm Med. 2012;2012.

22. Espinola-Zavaleta N, Soto ME, RomeroGonzalez A, Gómez-Puente L del C, Muñoz-Castellanos L, Gopal AS, et al. Prevalence of congenital heart disease and pulmonary hypertension in Down's syndrome: an echocardiographic study. $J$ Cardiovasc Ultrasound. 2015;23(2):72-7.

23. Anas M, Marlina U. Penggunaan Nitrovasodilator Sebagai Donor Oksida Nitrik Pada Preeklamsia. In: PROCEEDING. 2018.

24. Triastuti N, Airlangga MP, Anas M. Usage of Inhaled Nitric Oxides in Cases of Eisenmenger Syndrome. Indones J Med Sci Public Heal. 2020;1(1):13-9.

25. Zeng W, Lu X, Xiong C, Shan G, Liu Z, Ni $\mathrm{X}$, et al. The efficacy and safety of sildenafil in patients with pulmonary arterial hypertension associated with the different types of congenital heart disease. Clin Cardiol. 2011;34(8):513-8. 